\title{
Novas tecnologias da informação, escalabilidade e métodos quantitativos e qualitativos nas ciências humanas
}

\section{New information technologies, scalability and quantitative and qualitative methods in human sciences}

Silvana Seabra Hooper ${ }^{1}$ 


\section{Resumo}

O trabalho examina os pressupostos que orientaram a oposição entre os métodos quantitativos e qualitativos nas ciências humanas e sociais, tratando com destaque o aspecto da escalabilidade como problema epistemológico. Trata-se de retomar alguns pontos deste debate em face das novas tecnologias da informação (NTIs), focando no impacto da grande produção de dados. Compreendendo o método como lógica de investigação, a proposta retoma as discussões de Lev Manovich e Bruno Latour como referência para uma releitura da dicotomia entre os métodos quantitativos e qualitativos nas ciências humanas e sociais.

Palavras-chave

Pesquisa, novas tecnologias da informação, métodos quantitativos e qualitativos, Lev Manovich, Bruno Latour.

\section{Abstract}

This paper examines the assumptions that have guided the opposition between quantitative and qualitative methods in human and social sciences, focusing on the scalability aspect as an epistemological problem. It is about retaking some points of this debate regarding the new information technologies (NTI), focusing on the impact of large data production. Understanding method as research logic, the proposal retakes the discussions of Lev Manovich and Bruno Latour as a reference for a re-reading of the dichotomy between quantitative and qualitative methods in human and social sciences.

\section{Keywords}

Research, new information technologies, quantitative and qualitative methods, Lev Manovich, Bruno Latour. 


\section{Introdução}

Já se tornou um truísmo afirmar que as novas mídias estão alterando o mundo. Mas é igualmente verdade que, de modo correlato, ainda sabemos pouco sobre a extensão dos efeitos provocados pelas novas tecnologias da informação (NTIs). Isso porque a escala, a complexidade e a velocidade das transformações parecem se colocar muito à frente da compreensão humana. Muitos estudos e abordagens já existem e vêm se acumulando nas ciências humanas há algum tempo. Embora a discussão sobre as redes sociais não seja uma novidade no campo das ciências sociais e das humanidades², foi com o trabalho de Castells (1999) que o termo foi filiado definitivamente às NTIs. Na continuidade desses estudos, são notáveis, por exemplo, as propostas de Urry (2008), que apresentou uma concepção de sociedade caracterizada pelos fluxos de mobilidade, e os mais recentes trabalhos da sociologia/antropologia simétrica de Latour (2012) sobre a mediação tecnológica.

As diferentes concepções sobre as novas tecnologias e sua dinâmica social revelam, também, a passagem dos estudos que privilegiavam, no primeiro momento, os fenômenos das NTIs dentro de um contexto de complexidade global para, no decorrer dos anos, concebê-los como uma transformação social mais profunda. A consciência da extensão e profundidade das NTIs fez nascer a reivindicação por renomeações desses novos tempos, como "Era da informação", "Era do computador", ou "Era do digital", e por delimitações de novas áreas de estudos, por exemplo as Humanidades Digitais (BERRY, 2011; SCHNAPP, PRESNER, 2009) e os Software Studies (FULLER, 2008).

Dentre as várias características destacadas nesses estudos, uma das mais significativas é a que aponta a profunda alteração no modo de produção de conhecimento. Vários autores (BERRY, 2011; KITTLER, 2016) têm demonstrado que, além do seu caráter mediador inicialmente proposto, as novas tecnologias digitais também produzem consequências ontológicas e epistemológicas profundas. 
Embora envolva mais de um aspecto do processo cognitivo geral, uma das características mais visíveis das NTIs é o aumento exponencial de informações produzidas. O gigantismo dessa produção de dados, já comparado a um verdadeiro tsunami (RUPPERT, 2014), foi nomeado pelo acrônimo Big Data. Uma das primeiras definições para o termo recorreu à origem tecnológica, descrevendo-o como um termo aplicado a um conjunto de dados cujo tamanho exige tecnologia de hardware e software para a captura dos dados, arquivamento e análise (MANOVICH, 2012). Embora a questão quantitativa se destaque, vários pesquisadores chamam a atenção para o fato de que o conjunto de instrumentos e procedimentos constituem, também, um modelo cognitivo e epistemológico (BERRY, 2011; LATOUR, 2012).

A questão do Big Data, em particular mas não exclusivamente, reacendeu o debate metodológico, pois promoveu uma defesa dos métodos quantitativos em sua antiga oposição aos métodos qualitativos.

O que se segue aqui é uma tentativa de retomar alguns pontos do debate sobre os métodos quantitativos e qualitativos e sobre sua relação com a avalanche inusitada de informações disponibilizadas pelas NTIs, bem como sugerir, a partir de Manovich e Latour, ideias que reposicionem a clássica dicotomia entre tais metodologias e seus pressupostos.

\section{Humanidades, Big Data e a questão da escalabilidade}

As ciências humanas sempre se movimentaram entre as questões da escala dos dados. De um lado, coloca-se a defesa e a preocupação com a produção e interpretação de grande extensão de dados da pesquisa quantitativa, sugerindo um conhecimento mais extenso e com caráter preditivo ampliado; de outro, está a preocupação com a pequena escala e com o singular, em um viés que defende que a profundidade responderia melhor ao conhecimento do que à quantidade. Esse é um problema que já se manifestava nas discussões iniciais da fundação da Sociologia no final do século XIX e início do século XX. O estudo clássico de Durkheim, O suicídio, originalmente publicado em 1897, aplica a crença de que uma grande quantidade de dados poderia mostrar certos padrões sociais através da 
utilização da análise estatística. A defesa dessa linhagem se manifestará também, fortemente, nos anos 1950, em especial com Lazarsfeld (Escola de Chicago). Assim, a quantidade pode ser entendida menos como questão técnica e mais como problema epistemológico de fundo manifesto no conceito de escala.

Segundo McCarthy (2014), o conceito de escala desempenha importante papel para a definição da ciência moderna. Entre os vários conceitos de escala que surgiram na Idade Moderna, o seu sentido metodológico está diretamente relacionado às propostas de Bacon e ao empirismo do século XVII. Essa definição passa a ser usada para expressar as relações de proporção entre objetos e suas representações, permitindo uma ruptura com a metafísica, na qual o conceito de escala remetia à lógica de ascensão (escada, subida) numa ordem hierárquica dos seres à unidade (MCCARTHY, 2014). O conceito de escala não apena se tornou hegemônico, como também se aperfeiçoou ao estabelecer as relações proporcionais de maneira matemática e quantificada, de tal forma que

\footnotetext{
na representação proporcional, as relações entre o referente e o signo são exatas e quantificadas. O signo é uma reprodução fiel de alguns aspectos-chave do referente (suas proporções) e pode ser tratado como idêntico ao referente em certas circunstâncias. (MCCARTHY, 2014, p. 77)
}

Além disso, a escalabilidade também foi utilizada no aspecto lógico da produção de conhecimento, expressando-se na oscilação entre, de um lado, o dado empírico e singular e, de outro, na tentativa de produção de generalizações no nível mental, estabelecendo uma espécie de linha "como graus de um contínuo conceitual, abrangendo desde a materialidade em uma extremidade até a abstração na outra" (MCCARTHY, 2014, p. 79). Novamente, o empirismo é o exemplo de McCarthy, e Bacon é o pensador mais expressivo desse momento, pois deriva suas proposições teóricas (abstrações) de fenômenos empíricos, dos quais são a síntese.

Esse movimento é tão inovador quanto arriscado e se encontra no coração do empirismo: trata-se da questão do indutivismo. Segundo o princípio empirista, esse processo nos conduz dos chamados enunciados observacionais até os enunciados universais. A questão, também nomeada de "problema da indução", é estabelecer um 
"ponto de vista seguro" da passagem da empiria para a generalização. Como resposta, Bacon oferece a escala, já que, para ele, "todas as coisas ascendem por escala à unidade" (MCCARTHY, 2014, p. 76). Dessa forma, segundo McCarthy (2014, p. 77), a escala consiste na resolução das dicotomias "como uma linha de ação e retórica ativamente conectando pensamento e coisa, observação e especulação".

De acordo com McCarthy (2014), o sentido dado às relações da escala acabou por se estabelecer, se não como solução, pelo menos como procedimento crucial para o conhecimento moderno. Por isso, fazem parte de um mesmo quadro epistêmico as dicotomias entre argumento e empiria, totalidade e singularidade, método e técnica, e quantidade e qualidade, sendo que a última se expressa nas polêmicas entre as adequações dos métodos quantitativos versus os qualitativos. A compreensão dos limites desse desenho epistemológico significa admitir que o conhecimento sempre se dará por algum nível de escolha de um dos polos e que uma totalidade que almeje a conciliação ou a anulação das extremidades dicotômicas nunca será totalmente bem-sucedida.

Através do entendimento do princípio da escalabilidade, parece ficar claro que o que define a lógica da quantidade rege inevitavelmente o princípio da qualidade e que o seu princípio é epistemológico. Mais recentemente, essa discussão tem retornado à cena, muito em função das NTI, que criaram um novo patamar na produção quantitativa de dados, com alcance inédito. Se antes a escassez de dados era uma das preocupações mais imediatas das ciências sociais, hoje já se fala em termos de excesso.

\section{Metodologia quantitativas e qualitativas: o debate}

A escolha da metodologia é, se não a mais importante, uma das principais decisões de uma pesquisa. Entre os pressupostos dessa decisão encontram-se as questões referentes à empiria em sua dimensão de extensão (quantidade) e de significação (qualidade), expressas no último caso nos conceitos e categorias. Essas vertentes se dividem entre duas correntes metodológicas - a qualitativa e a quantitativa - que são, na maioria das vezes, entendidas como opostas, embora 
tenhamos desenvolvido uma terceira tendência, que apostou em vê-las como complementares ou intercambiáveis. As discussões sobre a propriedade de uma ou de outra metodologia geraram uma longa produção teórica que oscila, não apenas na adequação epistemológica, mas, em especial, na crítica e rejeição da metodologia preterida (SMITH, 1983).

Embora possa parecer recente, a origem desse debate remonta ao final do século XIX, cuja questão crucial era se os cientistas sociais poderiam e/ou deveriam empregar a mesma metodologia das ciências físicas naturais para investigar o mundo social e humano. De um lado, os positivistas, representados pela figura de Durkheim, defenderam que a realidade social, tal qual as ciências físico-naturais, é dirigida por leis invariáveis, que, por sua vez, são independentes da vontade humana e acessíveis em termo de conhecimento. Numa outra linhagem, aceita sob o rótulo geral de idealistas, estão Dilthey, Simmel e Weber com sua sociologia compreensiva, os quais também se localizam na mesma época, final do século XIX e início do XX. Segundo a última tendência, os fenômenos sociais são produtos da ação humana e, mesmo defendendo uma "ciência social" concebida em termos de rigor na produção de conhecimento, o intento não se condicionaria ao modelo nomotético anterior.

$\mathrm{Na}$ linhagem chamada de idealista, o objeto de estudo das ciências humanas é sui generis: possui características específicas, pois é histórica, mas sua natureza é basicamente qualitativa, uma vez que a realidade social é complexa. Portanto, as ciências sociais são ideológicas em sua essência, e a "visão de mundo do pesquisador e dos atores sociais estão implicadas em todo o processo de conhecimento, desde a concepção do objeto até o resultado do trabalho" (MINAYO, 1996, p. 20-21).

Essas duas formas de definir o campo das humanidades, embora quase sempre pensadas de forma antagônica, acabaram por se tornar parte do percurso do desenvolvimento das ciências humanas e sociais, sendo possível acompanhar a predominância de um ou de outro método em épocas distintas, sem que nenhum tenha superado o outro epistemologicamente.

Num estudo sobre documentação disponível na internet e acessível através do Google Scholar, Matos (2014) pesquisou a presença dos termos métodos 
quantitativo e qualitativo associados ao termo social (todos em inglês) desde 1900. A autora conseguiu contar as referências e mostrar o predomínio de um ou outro ao longo das décadas de 1900 a 1980 e de 1990 a 2010.

Os resultados mostram uma discreta primazia das citações do método quantitativo até o final dos anos 1990. Mas, a partir desse momento, o número de citações apresenta quase equivalência e, na década seguinte, prevalece a ocorrência do termo método qualitativo. Embora exploratória, essa pesquisa encontra confirmação, quando contraposta aos desenvolvimentos históricos das ciências sociais ao longo do século XX e início do século XXI, quando se alternaram os paradigmas de caráter mais positivista aos de formato mais hermenêutico ${ }^{3}$.

Como exemplo dessa associação, ao longo da expansão da Escola de Chicago se apresentou uma concentração significativa de pesquisas qualitativas. Na sequência, encontramos uma preponderância no uso das pesquisas quantitativas, por exemplo na Escola de Columbia ${ }^{4}$.

Com o passar do tempo, o debate se mostrou menos uma questão de técnica de coleta de dados e mais um índice da divergência sobre a natureza e a finalidade da pesquisa em ciências humanas e sociais (SMITH, 1983). Os exemplos citados estão majoritariamente inscritos na área da Sociologia, mas outros campos disciplinares não fugiram à regra, como a Psicologia, a Educação, a História ${ }^{5}$ e a Comunicação Social. Embora com objetos distintos, todas essas disciplinas mantêm o debate da objetividade versus subjetividade como uma das questões mais importantes para sua definição. Contudo, com as NTIs o campo comunicacional enfrenta, provavelmente como nenhum outro, o desafio de 
rediscutir sua metodologia de pesquisa, já que nele a questão da escalabilidade foi impulsionada mais dramaticamente.

Os estudos sobre tecnologia e sociedade consideram que o meio (a técnica), a exemplo do que foi proclamado por McLuhan em relação à comunicação, não é neutro. Por essa razão, a tecnologia não pode ser pensada como uma etapa independente. Por isso, tampouco as mudanças sob sua égide são meras adaptações de algo que aconteceu antes ou em algum outro lugar.

Soma-se a isso o fato de que as sociedades contemporâneas têm se tornado cada vez mais digitais com as NTIs e, por isso mesmo, mais autorreferenciais as ações humanas tendem a ser registradas digitalmente, produzindo um inevitável rastro de si. Isso garante a alta eficiência no funcionamento do sistema, contudo, a questão da segurança desses dados fica constantemente ameaçada.

Do ponto de vista da pesquisa e dos métodos, a sociedade em rede e o Big Data fizeram surgir, num primeiro momento, uma verdadeira onda de otimismo com relação às possibilidades de conhecimento. O cenário alargava fortemente as possibilidades de enriquecer os detalhes de nossas imagens do real, que até então se mostravam mais próximas do estilo impressionista de representação. A polêmica sobre as metodologias quantitativas e qualitativas, tanto nos aspectos que as opõe quanto nos que permitem sua complementariedade, enfrenta uma nova frente de questões. A inauguração de uma rede de dados rastreáveis e em dimensões incalculáveis, se não pode ser responsabilizada pelo novo debate, aponta para a recomposição do problema sobre o conhecimento.

\section{Latour e Manovich: novo paradigma e novas leituras dos métodos quantitativos e qualitativos}

As promessas geradas pelas NTIs com seus enormes bancos de dados estabeleceram posições distintas com relação às possibilidades de produção de conhecimento. Como em outras épocas, mudanças nos dispositivos de acesso ao conhecimento impulsionam um mal-estar difuso, que oscila entre a disposição 
máxima e o pessimismo latente. Essa mesma condição social acompanhou, por exemplo, o aparecimento da imprensa nos séculos XV e XVI6.

Em 2008, Chris Anderson, editor da prestigiada revista Wired, dedicada aos temas da tecnologia e cultura, publicou artigo no qual anunciava nada menos que o fim da teoria e a obsolescência do método científico. Segundo o autor,

este é um mundo onde grandes quantidades de dados e matemática aplicada substituem todas as outras ferramentas que podem ser usadas. Fora com todas as teorias do comportamento humano, da linguística à sociologia. Esqueça a taxonomia, a ontologia e a psicologia. Quem sabe por que as pessoas fazem o que fazem? O ponto é que eles fazem isso, e podemos rastreá-las e medi-las com uma fidelidade sem precedentes. Com dados suficientes, os números falam por si. (ANDERSON, 2008, tradução nossa $)^{7}$

A perspectiva de Anderson defende a primazia de um processo indutivo absoluto. Em nível nunca imaginado, porque absoluto, a soma das evidências tomaria, assim, o lugar da lógica dedutiva. O uso de algoritmos sobre uma massa gigantesca de dados substituiria as hipóteses, e teríamos o puro empirismo. A partir desse momento, o conhecimento prescindiria da teoria em favor da tecnologia. A visão de Anderson não é, contudo, hegemônica.

Não é a primeira e, provavelmente, não será a última vez que novidades no campo do conhecimento, sejam de ordem teórica sejam de ordem prática, esboçam as chamadas soluções derradeiras. Na área da Computação e no recente domínio das Humanidades Digitais, contudo, dominam avaliações bem mais parcimoniosas. Um pesquisador como David Berry (2011) avalia que as produções de dados através das NTIs remodelam o conhecimento, mas não dispensam o agenciamento humano. Segundo Berry (2011, p. 8), a escalada vertiginosa na produção de dados e informações Grafton (1998) têm mostrado que, longe da unanimidade, tais invenções promoveram várias e longas polêmicas em torno da sua função. 
fornece quantidades desestabilizadoras de conhecimento e informação que carecem da força reguladora da filosofia - que, como argumentou Kant, garante que as instituições permaneçam racionais. [...] A tecnologia possibilita o acesso aos bancos de dados do conhecimento humano de qualquer lugar, desconsiderando e contornando os tradicionais guardiões do conhecimento no estado, nas universidades e no mercado. Não parece mais haver o professor que the diz o que você deve procurar e os "três argumentos a favor" e "três argumentos contra isso". (BERRY, 2011, p. 8)

Essa situação de confusão promove, no entanto, uma busca por novas soluções e conduções na organização da produção e no acesso ao conhecimento. Berry sugere que, ao contrário do que afirma Anderson a respeito do fim da mediação científica, o momento atual é de transição até, pelo menos, que se construa nova arbitragem para o acesso à realidade, sem a qual seria, se não impossível, no mínimo confuso estabelecer formas confiáveis de conhecimento.

O que se evidencia, nesse caso, não é apenas a transição de métodos e técnicas tradicionais de pesquisa, mas também a formação de uma nova autoridade, isto é, uma nova forma de disciplina do saber em termos bem próximos dos sugeridos por Foucault (1981). Uma nova forma numa nova linguagem, pois com as NTIs adentramos num momento de revolução do paradigma. O conceito remonta a Kuhn (1997), para quem o paradigma se constitui como uma maneira específica de interrogar o mundo que, por isso mesmo, limita e sistematiza um conjunto de respostas. Ainda segundo Kuhn, periodicamente surgem novas formas de pensar que desafiam as abordagens usuais, as quais com o tempo podem oferecer uma nova hegemonia na forma de um novo paradigma. Tão importante quanto o conceito de paradigma é o entendimento de ciência normal, que é um conjunto complexo de meios através dos qual se resolvem os chamados problemas padrão definidos pelo próprio paradigma. Na maior parte do tempo, segundo Kuhn, a ciência opera dentro da "ciência normal" simplesmente alargando e aprofundando o próprio paradigma. Seria difícil afirmar com absoluta certeza que as NTIs engendraram um novo paradigma de conhecimento (em mais de uma área), até porque o próprio conceito de paradigma é, em certo sentido, vago e pertencente a um momento histórico determinado. 
De qualquer forma, a afirmação de Anderson (2008) sobre o fim da teoria promovido pelas NTIs, apontando para um movimento para fora do quadro de produção de conhecimento tradicional e cuja moldura significa a extinção de qualquer mediação, sugere mais um fascínio pela tecnologia do que uma realidade. Seriam vários os pontos a considerar na proposta de Anderson, mas, para efeito do nosso argumento central, dois são mais relevantes e merecem ser pontuados. O primeiro é que, embora a produção de dados dentro das NTIs tenha sido ampliada a um grau exaustivo, ela será sempre uma representação e, portanto, uma amostra. Em segundo lugar, considere-se a existência de uma produção enorme de dados e informações que não são exclusivamente humanos e que são produzidos e replicados pelas próprias máquinas, tanto sob a forma natural de desenvolvimento da inteligência artificial quanto sob a forma de criação de falsas informações. Embora a inescapável condição de parcialidade seja um fato, isso não significa que as NTIs possam ser equiparadas à outras formas de conhecimento. Autores como Manovich e Latour têm buscado compreender as novas tecnologias dentro de parâmetros significativamente diversos do que temos pensado até agora.

Lev Manovich é um nome obrigatório quando se trabalha com os novos métodos de pesquisa trazidos pelas NTIs. Seu livro The language of new media (2001) tornou-se, provavelmente, um dos textos mais lidos e citados sobre o tema. Embora oriundo das artes, Manovich é considerado pioneiro na definição do novo campo de estudos de software para o campo das humanidades. A proposta de Manovich deve ser lida no contexto da primeira fase de expansão da web, fase que já foi rotulada de "ideologia californiana"8. Trabalhando com grandes telas que organizam, classificam e analisam, o método prioriza a imagem direta em detrimento das tradicionais formas gráficas. A premissa do autor é que a Nova Mídia pode ser definida como linguagem fundacional, ou seja, como um conjunto 
de qualidades formais, mas também poéticas, que poderiam ser identificadas em todos os objetos da mídia.

O projeto de Manovich, que une as áreas da Computação Social e da Analítica Cultural [Cultural Analysis] enfatizando a segunda, se baseia numa discussão sobre a escala de nossas amostras e sua representatividade. No texto "A ciência da cultura? Computação social, humanidades digitais e analítica cultural", ele afirma acreditar que

os conteúdos da web e das redes sociais, e as atividades do usuário nos dão oportunidade sem precedentes para descrever, modelar e simular o universo cultural global enquanto questionamos e repensamos os conceitos básicos e ferramentas de humanidades que foram desenvolvidas para analisar dados culturais menores. (MANOVICH, 2015, p. 73)

A afirmação não é ingênua e nem o autor busca equalizar a proposta promovendo uma simples soma ou uma complementariedade dos métodos quantitativos e qualitativos que resolvesse a questão. Diferentemente disso, para ele, "um grande volume de dados culturais, o social e o cultural se sobrepõem estreitamente", produzindo uma sociologia da cultura mais fina, que mescla categorias da sociologia tradicional como renda e gênero, mas que considera uma infinidade de outras e novas classificações. Hoje

os cientistas da computação usam algoritmos para extrair milhares de características de cada imagem, um vídeo, um tweet, um e-mail e assim por diante. [...] podemos descrever todos que vivem em uma cidade de milhões de dimensões separadas extraindo todos os tipos de características de sua atividade de mídia social. (MANOVICH, 2015, p. 80)

Por meio desse uso massivo de dados, a Analítica Cultural cria uma nova possibilidade de pesquisa - wide data. Segundo Manovich (2015, p. 80),

os wide data oferecem uma oportunidade para repensar as suposições fundamentais sobre o que é a sociedade e como estudá-la; e da mesma forma, o que é cultura, uma carreira artística, um corpo de imagens, um grupo de pessoas com gosto estético semelhante e assim por diante. Ao invés de dividir a história cultural usando uma dimensão (tempo), 
ou duas (tempo e localização geográfica) ou um pouco mais (por exemplo, mídia, gênero), dimensões infinitas podem ser manipuladas.

É importante notar que, com Manovich (2015, p. 68-69), o debate sobre metodologias quantitativas e qualitativas se desloca para fora da usual dicotomia, mesmo porque não se trata de "escolher entre objetivos e metodologia humanística vs científica ou subordinar um[a] ao outr[a]". E, embora a palavra seja combinar, trata-se de visão bem mais extensa e mesmo estrutural, uma vez que

a Analítica Cultural está interessada em tudo que seja criado por todo mundo. [...] Similarmente, nós queremos olhar para cada manifestação cultural, ao invés de amostras seletivas. (Esta perspectiva mais sistemática não é dissimilar daquela da antropologia cultural.) (MANOVICH, 2015, p. 74, grifos nossos)

Em 2011, Manovich enfrentou novamente o problema das metodologias quantitativas versus as qualitativas em texto que versava sobre o Big Data. Esse texto postula que ambos os métodos possuem profundidade epistemológica equivalente e que sua diferença estaria localizada na escalabilidade e numa diferença de conteúdo.

É verdade que "a superfície é a nova profundidade" - no sentido de que as quantidades de dados "profundos" que no passado eram obtidos sobre alguns agora podem ser obtidos automaticamente sobre muitos? Teoricamente, a resposta é sim, desde que tenhamos em mente que os dois tipos de dados profundos têm conteúdo diferente. (MANOVICH, 2011, p. 13)

Conclusivamente

A ascensão das mídias sociais, juntamente com o progresso das ferramentas computacionais que podem processar grandes quantidades de dados, possibilita uma abordagem fundamentalmente nova para o estudo do ser humano e da sociedade. Não precisamos mais escolher entre tamanho de dados e profundidade de dados. Podemos estudar trajetórias exatas formadas por bilhões de expressões culturais, experiências, textos e links. O conhecimento detalhado e os insights que antes só poderiam ser alcançados sobre algumas pessoas agora podem ser alcançados com muito mais pessoas. (MANOVICH, 2011, p. 3) 
Em outra versão, Bruno Latour também tem pesquisado a questão das NTIs e de seu impacto metodológico. Responsável por uma perspectiva analítica que prioriza o papel dos processos científicos, Latour destaca o papel interativo que as questões técnico-sociais desempenham no desenvolvimento científico. A Teoria Ator-Rede (ANT) (LATOUR, 2012) prioriza os construtores da rede de produção de conhecimento e tecnologias, englobando interações entre teorias, pessoas, agências de financiamento, instituições variadas e mesmo governos numa lógica assimétrica. Como na semiótica, onde signos só podem ser compreendidos em relação a outros signos, a ANT postula que o ator (humano ou não humano) é "alguém" ou "algo", cuja atividade é definida pela atuação de outros atuantes. Por essa razão, na ANT o termo rede sociotécnica é utilizado como uma tentativa de superação da dicotomia entre humanos e não humanos. Desse nivelamento ontológico radical e, em decorrência, filosófico, seguem-se outros. Um dos mais relevantes para as ciências humanas reside no fim da perspectiva dual sobre os fenômenos sociais divididos em nível micro e macro. O resultado é que os métodos quantitativos e qualitativos não são mais opostos que estabelecem, por um lado, uma análise estatística (macroestrutural) e, por outro, uma observação etnográfica (microinteracional). Tal perspectiva está, segundo Latour e Venturini (2009, p. 88), sendo superada pela mídia digital que "oferece muito mais do que apenas outro campo para aplicar os métodos existentes: eles oferecem a possibilidade de reestruturar o estudo da existência".

Até agora, o acesso aos fenômenos coletivos sempre foi incompleto e caro. [...] Nas ciências sociais, fenômenos emergentes tornam-se estruturas, tabelas de classificação que hospedam e influenciam interações. Essa visão estruturalista deve-se em grande parte ao fato de as ciências sociais nunca terem tido métodos de reconectar micro e macro e mostrar como os fenômenos globais são construídos pelo conjunto de interações locais. A tecnologia digital promete revolucionar essa situação, proporcionando às ciências sociais a possibilidade de acompanhar cada segmento de interação e mostrando como a vida social é tecida em conjunto por sua montagem. (LATOUR; VENTURINI, 2009, p. 88-89)

A necessidade de abstrações referentes ao "coletivo" ou ao "social" passa, segunda essa leitura, a não mais produzir sentido numa configuração, pois agora as 
interações e conexões podem ser acompanhadas desde o indivíduo até formações coletivas maiores. Além disso, Latour e Venturini (2009, p. 100) observam que a separação entre as abordagens quantitativa e qualitativa produz uma versão pontual dos fenômenos, porque os capta em momentos estanques, ou "na melhor das hipóteses, as fases de transição entre períodos de estabilidade". Para os autores, a vida comum, isto é, social, é sempre uma combinação de momentos de estabilidade com momentos de mudanças, numa espécie de controvérsia constante, em que "as instituições sociais não são estruturas que se impõem aos indivíduos", mas que, ao contrário, são seus efeitos (LATOUR; VENTURINI, 2009, p. 101).

Assim, é ilusório imaginar que a dualidade metodológica supera a dicotomia própria ao mundo social. Ao contrário, a oposição metodológica é o que nos impede de uma melhor compreensão. Os métodos quantitativos destacam apenas os elementos de consenso, enquanto "os métodos qualitativos inibem qualquer compreensão de como os pontos de equilíbrio podem ser negociados temporariamente, deixando a controvérsia em aberto" (LATOUR; VENTURINI, 2009, p. 101).

A inspiração dessa perspectiva com ênfase na contingência, mas ao mesmo tempo longe de uma abordagem exclusiva dos indivíduos ou grupos sociais, Latour trouxe da sociologia de Gabriel Tarde (1843-1904). Contemporâneo de Durkheim, Tarde criticava a concepção de totalidades acabadas e focava nas interações e práticas sociais.

Duas afirmações de Gabriel Tarde são, para Latour (2002, p. 146), fundamentos epistemológicos:

a) a divisão entre natureza e sociedade é irrelevante para a compreensão do mundo das interações humanas;

b) a distinção micro/macro sufoca qualquer tentativa de entender como a sociedade está sendo gerada.

Nessas premissas, se baseia a sugestão de ver Gabriel Tarde como precursor intelectual da Teoria Ator-Rede. Além disso, o conceito leibniziano de mônada é 
crucial para a montagem das semelhanças que Latour traçará entre Tarde e sua própria concepção social, pois as mônadas são definidas por Leibniz como

partículas elementares, as substâncias simples de que os compostos são feitos. Elas são, portanto, diferenciadas (dotadas de qualidades que as singularizam umas em relação às outras) e diferenciantes (animadas por uma potência imanente de mudança contínua ou de diferenciação). Além disso, ou por isso mesmo, elas dizem respeito às nuances ao infinitamente pequeno, ao infinitesimal que constitui toda (a) diferença. (VARGAS, 2004, p. 173, grifos do autor)

O conceito traz a ideia da diferença como fundamento epistemológico, pois renuncia "ao dualismo cartesiano entre matéria e espírito e àqueles que lhe são correlatos" (VARGAS, 2004, p. 173). Tarde define a mônada dentro de uma perspectiva relacional - o que uma mônada tem é o que o todo possui, ou "o todo é sempre menor do que as partes", como nos lembra Latour com expressão retirada de Tarde.

O conceito de mônada pode ser aplicado a qualquer época social. Por isso, é uma lente útil e um recurso heurístico que nos permite enxergar o mundo em comunidades e coleções em interação contínua. E, embora, como afirma Latour, nenhum método, incluindo os digitais, possam nos oferecer uma visão panóptica da vida coletiva, é certo que as NTIs nos oferecem, pela primeira vez na história das ciências sociais, uma visão menos contínua, que pode ser estendida desde a menor interação até as maiores, chamadas macroestruturas. Sobretudo, o que mudou com as NTIs foi a velocidade com que os dados, de maneira individual ou agregada, podem ser acessados. É dessa forma que as NTIs, de acordo com Latour, podem significar o estabelecimento de um novo olhar metodológico que supere a questão de metodologia quantitativa ou qualitativa. Afinal ainda é possível medir e centrar-se num único elemento, mas a análise monádica torna possível mudar o foco, que ganha sentido dentro do processo interativo de observação do movimento.

\section{Observações conclusivas}

As NTIs oferecem novas e desafiantes oportunidades de renovação da pesquisa social, mas ainda estamos tateando o seu potencial completo. No plano 
metodológico, onde desde a fundação das ciências sociais estamos imersos na polêmica entre análises macro ou microssociais, parece razoável supor que o novo cenário da internet e da digitalização seja compreendido dentro da lógica simples de escalabilidade. A produção de dados de forma agigantada pode sugerir a adoção definitiva de estratégias quantitativas de pesquisa. De fato, tal proposta rodeia as discussões metodológicas e ganha adeptos, o que é exemplar na postura de Anderson (2008) sobre a substituição do método científico pelas análises quantitativas e seus algoritmos. Por outro lado, é verdade também que muitos têm observado essa tendência apenas como mais uma caracterização da desumanização decorrente da tecnologia, recrudescendo o velho debate da máquina versus humanidade. Em outra vertente, autores como Manovich e Latour e teóricos das Humanidades Digitais e do Big Data apontam para um desenho bastante original, que pode alterar, inclusive, a própria moldura na qual se processa essa polêmica.

Ainda não é claro se podemos qualificar e nomear essa terceira via do debate como um novo paradigma (Kuhn), que estaria se formando. Contudo, seu caráter de ruptura, com certeza, se localiza no abandono da discussão da escalabilidade como problema de quantidade, que resulta sempre na escolha de métodos quantitativos ou qualitativos. Portanto, pode-se falar, se não em termos de uma revolução paradigmática, pelo menos numa nova agenda de pesquisa.

Uma das certezas que vai se afirmando é o fato de que a compreensão do mundo em termos de macro e micro, humano e não humano, sujeito e objeto, entre outros, fica cada vez mais questionável. Essas abordagens dualistas, onde as metodologias quantitativas ou qualitativas eram as vias certas ou erradas de resolução do problema, são definidas como parte do próprio arcabouço na construção do problema e, portanto, como parte dele. Há, nessa leitura, uma admissão de uma verdade já contida no conceito de paradigma de Kuhn: a solução de um problema científico também é parte de um paradigma. Talvez seja mais importante observar que as NTIs trouxeram para o centro do debate, não apenas a questão da escolha de método, do nível de escala da amostra ou da dicotomia entre compreensão ou medição, mas o debate ontológico sobre a natureza da existência. 


\section{Referências}

ANDERSON, C. The end of theory: the data deluge makes the scientific method obsolete. Wired, São Francisco, v. 16, n. 7, 2008. Disponível em: https://bit.ly/2cBN4OE. Acesso em: 12 dez. 2018.

BERRY, D. M. The computational turn: thinking about the digital humanities. Culture Machine, Sussex, v. 12, p. 1-22. 2011.

BLAIR, A. M. Too much to know: managing scholarly information before the Modern Age. New Haven: Yale University Press, 2010.

BURKE, P. Uma história social do conhecimento. Rio de Janeiro: Zahar, 2012.

CASTELLS, M. A sociedade em rede. São Paulo: Paz e Terra, 1999.

DURKHEIM, E. O suicídio: estudo de sociologia. São Paulo: Martins Fontes, 2011.

FREEMAN, L. C. The development of Social Network analysis. Vancouver: Empirical Press, 2004.

FOUCAULT, M. As palavras e as coisas: uma arqueologia das ciências humanas. São Paulo: Martins Fontes, 1981.

FULLER, M. (ed.). Software studies: a lexicon. Cambridge: The MIT Press, 2008.

GRAFTON, A. As origens trágicas da erudição: pequeno tratado sobre a nota de rodapé. Campinas: Papiros, 1998.

KITTLER, F. A verdade do mundo técnico: ensaios sobre a genealogia da atualidade. Rio de Janeiro: Contraponto, 2016. 
KUHN, T. A estrutura das revoluções científicas. 5. ed. São Paulo: Perspectiva, 1997.

LATOUR, B. Gabriel Tarde and the end of the social. In: JOYCE, P. (ed.). The social in question: new bearings in history and the social sciences. Londres: Routledge, 2002. p. 117-132. Disponível em: https://bit.ly/2JUM9vl. Acesso em: 25 jan. 2019.

LATOUR, B. Tarde's idea of quantification. In: CANDEA, M. (ed.). The social after Gabriel Tarde: debates and assessments. Londres: Routledge, 2010. p. 145-162. Disponível em: https://bit.ly/2kwMSH4. Acesso em: 29 jan. 2019.

LATOUR, B. Reagregando o social: uma introdução à Teoria do Ator-Rede. Bauru: Edusc; Salvador: Edufba, 2012.

LATOUR, B; VENTURINI, T. The social fabric: digital traces and quali-quantitative methods. In: PROCEEDINGS OF FUTURE EN SEINE, 1., 2009, Paris. Anais [...]. Paris: Cap Digital, 2009. p. 87-101. Disponível em: https://bit.ly/1EkXFBc. Acesso em: 25 jan. 2019.

MANOVICH, L. A ciência da cultura? Computação social, humanidades digitais e analítica cultural. Matrizes, São Paulo, v. 9, n. 2, p. 67-83, 2015.

MANOVICH, L. The language of new media. Cambridge: The MIT Press, 2001.

MANOVICH, L. Trending: The promises and the challenges of big social data. Manovich. net, [S. I.], 2011. Disponível em: https://bit.ly/1KkzKHh. Acesso em: 25 jan. 2019.

MANOVICH, L. Trending: the promises and the challenges of big social data. In: GOLD, M. K. (ed.). Debates in the digital humanities. Minneapolis: University of Minnesota Press, 2012. p. 460-475. Disponível em: https://bit.ly/2m1vxpY. Acesso em: 25 jan. 2019. 
MATOS, M. Metodologias qualitativas e quantitativas: de que falamos? Fórum Sociológico, Lisboa, v. 24, 2014. Disponível em: https://bit.ly/2kwOFfg. Acesso em: 25 jan. 2019.

MINAYO, M. C. S. O desafio do conhecimento: pesquisa qualitativa em saúde. Rio de Janeiro: Abrasco; São Paulo: Hucitec, 1996.

MCCARTHY, A. Do ordinário ao concreto: estudos culturais e a política de escala. Trama Interdisciplinar, São Paulo, v. 5, n. 3, p. 75-106, 2014.

RUPPERT, E. Social consequences of Big Data are not being attended to. [Entrevista cedida à] M. Carrigan. LSE Impact Blog, Londres, 2014. Disponível em: https:// bit.ly/2kXgjSF. Acesso em: 25 jan. 2019.

SCHNAPP, J.; PRESNER, P. The digital humanities manifesto 2.0. Humanities Blast, Los Angeles, 2009. Disponível em: https://bit.ly/1HWvXgP. Acesso em: 2 out. 2018.

SMITH, J. K. Quantitative versus qualitative research: an attempt to clarify the issue. Educational Researcher, Nova York, v. 12, n. 3, p. 6-13, 1983.

URRY, J. Mobilities. Malden: Polity Press, 2008.

VARGAS, E. V. Multiplicando os agentes do mundo: Gabriel Tarde e a sociologia infinitesimal. Revista Brasileira de Ciências Sociais, São Paulo, v. 19, n. 55, p. $172-176,2004$. 